\title{
An overview of bench design for cut slopes with an example of an advanced dataset assessment technique
}

\author{
S Coetsee Reutech Mining, South Africa
}

\begin{abstract}
The empirical derivation of the minimum berm width and the formulae presented by the various design criteria are different due to the input parameters selected, thus resulting in a range of minimum berm widths that can be calculated for the same set of rock mass and geometric conditions.

When compiling a berm design model, in assigning a derived (calculated) friction angle and cohesion value, the Factor of Safety (FoS) and Probability of Failure (PoF) for a suite of kinematically identified plane or wedge sliding instabilities may be overestimated and may not representative of true mining conditions.

Rather than applying dataset cutoff criteria to the FoS or PoF for plane or wedge instability spill volume, the use of all data regardless of the FoS or spill volume is required in order to accurately assess the minimum berm width that can be calculated and then recommended for the design. This is based on the assessment of all spill volumes, spill radii and the criteria accepted and applied.

As shear strength properties changeover the life-of-mine, so does the FoS. Assuming that the FoS is static and the derived PoF is indefinitely valid will result in a design that may be insufficient in maintaining the berm retention factor assigned.

Therefore, attaining and utilising derived FoS and PoF allows for all plane and wedge shape iterations compiled during the modelling process to be utilised. This methodology allows for the assessment of the minimum berm widths calculated using the published criteria and advanced dataset assessment techniques.
\end{abstract}

Keywords: bench design, shear strength parameters, berm retention factor

\section{Introduction}

Bench height and berm width contribute to the inter-ramp geometry on which an overall slope design is based. It is imperative to ensure that the inter-ramp geometry is empirically sound and that the design berm width is sufficient to maintain the berm retention factor required and therefore, the anticipated volume of failed material, should an instability occur. The berm retention factor, rock mass and geometric conditions of the discontinuities for the selected design sector inevitably define the berm width during the design process.

This berm retention factor is of paramount importance for the mitigation of rockfall, dependent on the percentage of the volume of material that exceeds the berm width.

Bench design analysis is usually conducted using published criteria such as the Ritchie Criterion (Ritchie 1963), the minimum berm width (Piteau \& Martin 1977), the Modified Ritchie Criterion (Hustrulid et al. 2001), the minimum berm width using either conical or pyramidal spill radius (Gibson et al. 2006, adapted and applied by Rocscience) and the minimum berm width presented by Haines et al. (2006).

These criteria are either empirical or formula-based, and typically encompass varietals of input parameters such as the bench height, bench face angle, plunge of the intersection of the joints, the angle of repose, the volume of spill material and the bulk or swelling factor.

The likelihood of achieving a design is highly reliant on attaining the bench face angle with specific reference to the bench crest due to break back as well as frozen toes. Break back is controlled by the local geology and 
the reduction in shear strength of the structures due to the blast and excavation cycle, and weathering over the life-of-mine. Frozen toes occur due to errors in pre-split application.

When compiling a berm design model, in assigning a derived (calculated) friction angle and cohesion value, the Factor of Safety (FoS) and Probability of Failure (PoF) for a suite of kinematically identified plane or wedge sliding instabilities may be overestimated and may not be representative of true mining conditions.

The friction angle may be assigned based on values that are residual, weakened or averaged, or a sensitivity analysis as described by Piteau \& Martin (1977), Whyatt et al. (2004), Gibson et al. (2006) and Jermy et al. (2011), respectively.

The cohesion value may be assigned based on $0 \mathrm{MPa}$, a weakened state or a sensitivity analysis as described by Piteau \& Martin (1977), Gibson et al. (2006), Whyatt et al. (2004) and Jermy et al. (2011), respectively.

The friction angle and cohesion value should be assigned based on nominal and static values or by applying a sensitivity analysis approach. The cohesion value especially should be reduced to account for field conditions as slope displacements could have degraded the natural cohesion within the discontinuities. These reduced values take into consideration the reduction in shear strength of the structures over the life of a mine.

Rather than applying dataset cutoff criteria to the FoS or PoF for plane or wedge instability spill volume, the use of all data regardless of the FoS or spill volume is required in order to accurately assess the minimum berm width that can be calculated and then recommended for the design. This is based on the assessment of all spill volumes, spill radii and the criteria accepted and applied.

As shear strength properties changeover the life-of-mine, so does the FoS. Assuming that the FoS is static and the derived PoF is indefinitely valid will result in a design that may be insufficient in maintaining the berm retention factor assigned.

Therefore, attaining and utilising derived FoS and PoF allows for all plane and wedge shape iterations compiled during the modelling process to be utilised. This methodology allows for the assessment of the minimum berm widths calculated using the published criteria and detailed dataset analyses techniques.

It is suggested that two plots illustrating the percentage of instabilities per spill radius bin (metre increments) and the break back distance range per spill radius (same metre increments) be compiled using the datasets from each planar and wedge combination model per selected section line without any design criteria being applied to first assess the worst-case scenarios.

This analysis provides a realistic assessment of the minimum berm width required per section line, per failure mode. This is especially pertinent as the conditions of the joints in the bench face cannot be accurately allocated. Practical considerations such as ravelling, blast spill from higher cuts, the time period of exposure, climate and weathering such as freeze and thaw cycles and blasting practices have an effect on the shear strength of the joints over the life-of-mine.

By comparing the minimum berm width and the anticipated break back associated per geometric iteration for planar or wedge sliding, the effective berm width can be evaluated and compared to the berm width for design, validation or optimisation.

This allows for a robust design approach that encompasses all eventualities and will ensure that the berm retention factor is valid for the life-of-mine.

The test of the design is to determine how well it measures up to and incorporates design rules that can be deemed standard or best industry practice at the time of this work. 


\title{
2 Bench design: an overview of current best practice principals
}

Hoek \& Bray (1981) discussed the importance of understanding bench scale instability. Whilst rock slope engineering has developed significantly over the last few decades, the fundamental principles of bench design remain the same, as outlined:

\begin{abstract}
"While overall slopes are important in terms of the economics of the mining operation, of more immediate concern is the stability of individual benches on a day-to-day basis. Failures on a bench scale may cause severe disruptions to the mining programme, should the infrastructure such as haul roads, property boundaries etc. be affected. Similarly, the safety of the working area in the vicinity of the bench face especially during excavation, scaling and cleaning and the preparation of subsequent drill and blast blocks is of utmost importance. It is these relatively small failures which occur with very little warning, that lives can be lost and equipment damaged".
\end{abstract}

It is these daily safety concerns that make bench design, and the understanding of bench scale failure is paramount from a production and monitoring perspective.

The stability of the individual bench is controlled by the local geological conditions, the geometry (orientation and angle) of the overall slope in the area, the groundwater conditions and the excavation technique.

If the listed factors, as well as the blast damage and long-term weathering effects can be quantified, the conditions which result in slope instabilities can be recognised and mitigated accordingly during the design process. Controlled blasting techniques, support and dewatering strategies can be considered and employed.

\subsection{The bench analysis programme}

It is important at the onset of a bench analysis programme to define the outcomes in completing the study. For example, these may include the validation and generation of new slope design, validation of an existing slope design, validation of the actual, opposed to designed slopes excavated, optimisation of a design that may include the whole pit slope, or designated zones within the pit for a future cut or the identification of bench scale instabilities that require control, and the design of the control system. In conducting a bench analysis for slope design purposes, the methodology described by Hoek \& Bray (1981) may be applied.

\subsection{Bench and berm functionality in slope design and bench design aspects}

The principal functions of a berm, in terms of an inter-ramp or slope design, is to provide a safe environment near the slope face for personnel and equipment to operate. Bench and berm design must therefore satisfy these standards (Read \& Stacey 2009):

- Reliability, which requires stable bench faces and bench crests. Joint geometry and the related shear strength properties define this.

- Safety, which requires that berm widths are sufficient to arrest and mitigate the danger of instability and related rockfall and to contain any spillage from the benches above.

- Long-term access to the berms for monitoring and the clean-up of spillage and rockfall.

In designing the bench face height and angle, and the berm width, consideration of the following bench design aspects are required (Read \& Stacey 2009):

- In many cases, it is not economically feasible to design an inter-ramp slope that allows the berms to catch each and every potential instability. As such, a limit is applied to the volume of material that a berm should accommodate. This is typically between 70 and $85 \%$. The berm capacity factor is defined by the mine owners as an accepted level of risk.

- A swell factor, dependent on the type of material, should be applied in order to estimate accurate volumes of spilled material. 
- The angle of repose, also defined by the type of material should be applied to accurately reproduce the spill dimensions, which further define the applicable berm width.

Based on these input parameters, the radius of the spilled material may be derived, which allows for the calculation of the minimum berm width required to arrest and hold failed bench scale instabilities and rockfall.

\subsection{Likelihood of achieving the design}

The likelihood of achieving a bench design is principally based on achieving the designed toe position of the bench face (known as frozen toe when the toe is not established) and minimising the back-break distance behind the crest.

Both of these factors are controlled by the local geology and the reduction in shear strength of the structures due to the blast and excavation cycle, or due to weathering over a long period of time. Excessive or poorly designed blasts cause significant damage to the rock mass volume in the vicinity of the slope. The usable width of the berm may be defined as the designed berm, minus the frozen toe or back-break of the crest due to blasting or structural crest failure.

Blast and excavation effects extend behind the slope face and can influence the stability of the geologic structures in that volume of rock mass. Blast-related damage includes extension of existing fractures, creation of additional fractures (by opening closed geological features or the creation of new blast or mechanical fractures) and displacement of structural surfaces resulting in a loss of cohesion and friction and creation of instantaneous excess porewater pressure.

\section{Bench design analysis considerations}

The principal design analysis considerations are discussed in the proceeding sections.

\subsection{Failure geometry}

With planar failure, Gibson et al. (2006) discuss the significant consideration of the fact that essentially one major plane for sliding to take place and a release plane on one or both ends is required. Planar failure can therefore be said to mimic highly asymmetric wedge shapes, whereby one joint surface is oblique to the bench face and sliding occurs mainly on this surface.

Based on this reasoning, planar and wedge shape failures may be assessed by the same method in order to ascertain minimum berm width requirements.

In order to correctly calculate the volume of failed material, the true geometric shape should be included as part of the input parameters for the analysis. The volume of material is directly proportional to the plunge of the line of intersection between the two joints as this dictates the size of the wedge.

\subsection{Friction angle}

The allocation of the friction angle for a bench design analysis may be based on the following rationale:

- Piteau \& Martin (1977) assume a residual friction angle in order to portray field opposed to laboratory conditions.

- Whyatt et al. (2004) weaken the discontinuity strength with the friction angle being reduced from saw cut to in situ values.

- Gibson et al. (2006) assume an average friction angle as it is deemed to be more realistic.

- Jermy et al. (2011) conduct a sensitivity analysis of the friction angles for wedge geometries with an FoS $<1.2$ in their study.

These methods are all based on the reduction of the friction angle to replicate true field conditions, as production activities have a profound effect on the shear strength of the discontinuities. 


\subsection{Cohesion}

The allocation of the cohesion value for a bench design analysis may be based on the following rationale:

- Piteau \& Martin (1977) assume a cohesion value of O MPa to account for field conditions.

- Gibson et al. (2006) assume a cohesion value of $0 \mathrm{MPa}$, as they reason slope displacements have occurred and destroyed the natural cohesion within the discontinuities.

- Whyatt et al. (2004) weaken the discontinuity strength but do not specify how this is applied to the cohesion value.

- Jermy et al. (2011) conduct a sensitivity analysis of the cohesion value for wedge geometries with an FoS $<1.2$ in their study.

Displacement on discontinuities caused by the drill and blast cycle will result in the loss of both friction and cohesion. Whilst these publications have reduced the cohesion value to $0 \mathrm{MPa}$, it is pertinent to assess if the structures do indeed have no cohesion as this would result in higher rates of failure and may affect the results of a bench design assessment.

\subsection{Defect waviness}

Whyatt et al. (2004) is the only publication that discusses defect waviness for bench design. In their study, the discontinuity waviness was removed. However, they do note that removal of the macro condition of the discontinuity must be tested independently of the friction and cohesion angle in order to correctly calibrate the models, or else there is the risk of overcompensating for blasting effects and therefore designing a more conservative slope.

\subsection{Hydrogeology}

The incorporation of the hydrogeological conditions for a bench analysis is discussed by Piteau \& Martin (1977) whereby they assume for the case study that the conditions were dry based on field observations. However, no other publication addresses how to incorporate water conditions accurately as an input parameter. Roscience RocPlane and SWedge software allow for a water-filled tension crack to be applied. Based on the methodology proposed in this paper, all valid geometric iterations are assessed, therefore, regardless of the groundwater conditions, each and every instability has been mitigated for. From an operational and monitoring perspective, instability during the wet season or due to higher than normal porewater pressures are likely to induce failure and should be addressed as a trigger mechanism for failure as part of the trigger action response plan (TARP).

\subsection{Angle of repose}

The angle of repose is defined as the maximum angle at which material remains stable when not found in its in situ state. The angle of repose is dependent on the material itself and the size of the contributing particles which form the slope of the material.

The angle of repose is an important parameter in defining the minimum berm width required, as the spill width of the failure is directly proportional to the value allocated. Martin \& Piteau (1977) and Gibson et al. (2006) include the angle of repose in their design criteria for minimum berm width.

Martin \& Piteau (1977) assumed that the failed material will rest at the angle of repose, which is typically between 35 and $40^{\circ}$. The angle of repose can be calibrated by back-analysis of previous or existing failures. 


\subsection{Bulk or swell factor}

The bulk or swell factor is applied to the derived failure volume in order to represent the new volume of space that the failed material will fit into, as it is no longer in situ. This factor is allocated based on the material being assessed.

Piteau \& Martin (1977) do not consider a bulk or swell factor in their minimum berm width formulae. However, a bulking factor may be applied to the minimum berm width after it has been calculated. Gibson et al. (2006) include a bulk factor in their formulae.

Haines et al. (2006) assume that a value of 1.5 for the bulk or swell factor is acceptable, as do Holley et al. (2006). Values between 1.3 and 1.5 are considered to be acceptable limits for a bench design analysis.

\subsection{Break back cells}

Miller (1983) provides the first insight into break back cell distribution and the probability of sliding per predefined break back cell. The probability that a certain berm width can be attained based on the joint probability stability is also discussed with the relevant formulae presented in order to calculate this. This is a concept that is later applied to the Rocscience RocPlane and SWedge software application.

The number of units, or cells that can be analysed for berm width, is dependent on the number and size of the windows, the discontinuity spacing, length and engineering judgment. It is important to vary the analyses to test the sensitivity to certain parameters to correctly ascertain the critical failure modes and their respective break back distances. Stability charts may then be compiled per overall slope angle for the berm width, allowing for the probability of retaining the berm width to be taken into consideration.

Miller et al. (2000) present the concept of blasting layout being designed with the intent to produce benches of a certain width. It is unlikely that the berm width will actually be retained after blasting and excavation. The paper is adapted from Miller (1983) and expands on the break back cell concept whilst providing a formula for computer-based modelling. The berm design and rockfall assessments must consider the predicted, operational catch-bench geometry and not the originally designed and ideal geometry. Tension cracks at the crest have not been incorporated as part of the cell break back probability theory.

\subsection{Geotechnical design considerations}

Geotechnical design considerations, when conducting a bench design include:

- Deep-seated failure which is to be addressed by other more detailed methods (Piteau \& Martin 1977).

- That the geotechnical model is well defined with specific emphasis on the structural model from both a major and minor discontinuity perspective. The orientation, geometry and spatial distribution of the structural features should be described per design sector in collaboration with the proposed orientation and potential geometry of the pit slopes (Piteau \& Martin 1977).

- The probable modes of failure are dependent on the various combinations of the identified joints sets should be identified along with a probability distribution for the probability of occurrence for certain wedge formations. Wedge shape formation can be based on stereographic projection techniques (Piteau \& Martin 1977).

- The importance of defining failure for individual benches as well as failure of the overall slope. It may be found that the PoF for an overall slope is often low with regards to failure on major faults or weak zones, while the design of individual benches against excessive failure may be the controlling factor for the design of the overall slope (Martin \& Piteau 1977).

- Alternative slope geometry and slope orientation should be considered in collaboration with the defined discontinuities (Martin \& Piteau 1977). 
- Hustrulid et al. (2001) places emphasis on assessing the orientation of slope with respect to discontinuities as the mode of failure can be amplified or reduced based upon the final pit limits. This is an especially pertinent point as many pit slopes have been designed without full comprehension of the impact of slope orientation.

- The bench faces require adequate cleaning and scaling to reduce rockfall and localised failure occurrence. Achievable bench face angles are defined by the rock strength, geological characteristics and by drill, blasting and excavation techniques (Hustrulid et al. 2001).

- The option of multiple benching in pits has some benefits which are described in Hustrulid et al. (2001):

- To provide steeper inter-ramp or overall pit slopes. Berm widths do not need to be doubled should the bench face be doubled, thus resulting in a steeper slope.

- To improve working conditions by leaving a wider, more accessible berm from which to base operations.

- To improve the reliability of catch berms as they are wider, by default, in order to minimise the effect of crest lost.

- To minimise the occurrence of areas where there is no catch berm left in the slope due to complete loss (anticipated or due to poor rock conditions or blasting and excavation).

- Ritchie (1963) describes the use of containment ditches dug into the berm. Hustrulid et al. (2001) states that whilst ditches may not always be possible, should space allow, tailings windrows are highly useful in rockfall and failure containment.

- The amount of break back of the crest locally rather than the bench face angle, that is of most concern during the design process. The majority of break back occurs on structures that are located in close proximity to the bench crest, should the discontinuities be flatter in this portion of the bench face, crest break back can be significant (Hustrulid et al. 2001).

\subsection{Design approaches}

Martin \& Piteau (1977) propose two principal design approaches. The first is a conservative approach whereby the slope is designed so that little or no failure occurs, and if it does these minor failures are caught on berms and removed as required. The second is a thorough consideration of the slope geometry, and an optimised design that will result in a managed approach toward failure. Berms should be designed to allow for later access for regular clean-up of failure. Inclined bench faces reduce the likelihood of high stresses at the bench face crest and therefore minimise tension cracks and subsequent loss of the crest and also reduce rockfall.

Carvalho (ca. 2012) presents a managed approach to bench design similar to that of Martin \& Piteau (1977) whereby a more detailed assessment is made of the design for optimisation. A design reliability of $80 \%$ is considered acceptable, thus allowing for $20 \%$ of plane- and wedge-shaped failures to occur.

A technique that can be utilised is the cumulative frequency analysis whereby the potential for a plane to slide within a pre-determined daylighting window, 50 to $60^{\circ}$ wide and 25 to $30^{\circ}$ on either side of normal to the bench face is calculated and the cumulative frequency of the failed planes is plotted against the bench face angle. For a wedge to slide, the pre-determined daylight window is typically $90^{\circ}$ wide and $45^{\circ}$ on either side of the normal to the bench face, similarly the cumulative frequency of the failed planes is plotted against the bench face angle (Carvalho ca. 2012).

By plotting the cumulative frequency of the failed planes or wedges against the bench face angle, a $20 \%$ acceptance cutoff can be applied. The Carvalho (ca. 2012) study was based on a kinematic approach and therefore, only defined kinematic or vector failure possibilities opposed to detailing the minimum spill berm widths required. 
Minimum berm width can be ascertained utilising the methodologies presented in Piteau \& Martin (1977), Martin \& Piteau (1977), Pierson et al. (1994), Hustrulid et al. (2001), Miller et al. (2000), Gibson et al. (2006) or Haines et al. (2006).

In open pit design, it is considered acceptable to trade-off a certain amount of bench scale failure for steeper bench face angles, but without compromising safety, as it is more economical to schedule regular berm clean-ups than to have much higher stripping ratios (Carvalho ca. 2012).

Abrahams (2015) states that the requirements of a bench and berm design are effectively the amount of back-break anticipated, the volume of material that is expected to fail and the minimum berm width that is required. It is important to define the expected and average conditions of the pit slope to include in an analysis.

The general approaches adopted when conducting a bench analysis, whether conservation or managed, include:

- A detailed bench and berm design without exposure has limited value as the design is not calibrated.

- It is preferable to start with an empirically sound slope and base the inter-ramp geometry on the derived overall slope angle.

- The acceptance criteria are based on the geotechnical conditions and operational requirements and capability.

Abrahams (2015) discussed the two principal approaches to slope design which are to either start with bench scale and to build stacks, or to start with an inter-ramp slope and assign a geometry that will fit. This is very dependent on the geotechnical conditions at the project site and the design criteria defined for the study, however, a sound inter-ramp slope is a more reliable design option from a stability perspective.

\subsection{Dataset assessment methods}

Piteau \& Martin (1977) conducted a study whereby the FoS was calculated for different wedge shapes and sizes based on the defined joints. The maximum plunge for the wedges with an FoS $>1$ was then derived and used in the proceeding bench design analysis, thus an FoS cutoff of $>1$ was applied.

Hafid Baroudi et al. (1992) state that the traditional analysis method provides information typically on the largest wedge by volume, opposed to smaller accumulative wedges over the distance of the bench face, which may actually result in a larger failed volume of material. The dataset of derived viable iterations is split based on the volume of the proposed wedge.

Holley et al. (2006) present an interesting theory of removing all model iterations with an FoS $>1.1$. It was envisaged due to the experience of the authors that the features with an FoS $<1.1$ were stable.

Holley et al. (2006) eliminate potential failures that were either too small and therefore likely to be removed by blasting or too large and therefore unlikely to occur. The largest $20 \%$ and the smallest $40 \%$ of failures by volume were removed from the dataset.

Jermy et al. (2011) focused specifically on generated wedge iterations that had FoS values between 1.2 and 1.8 for larger spill volumes. The sensitivity of the FoS for larger failures $<1.2$ was defined.

Grenon \& Laflamme (2011) build on the work from Grenon \& Hadjigeorgiou (2010) by focusing on incorporating design criteria to the integrated analysis of inter-ramp and bench stability. Both kinematic and limit equilibrium assessments of the derived pit slopes were conducted. The bench analysis cutoff for the FoS was $<1.1$ similar to that in the study conducted by Holley et al. (2006).

Coetsee (2014) recommends the utilisation of all iterations regardless of FoS or volume and to calculate the cumulative percentage of spill radii that will exceed a selected berm width, thus not splitting the dataset. 


\subsection{Probabilistic analysis for break back assessment}

Hustrulid et al. (2001) presents the importance of defining structures that may affect bench crest stability as part of a probabilistic analysis that takes the occurrence, orientation, length, spacing and shear strength of the discontinuities into account. The maximum distance of break back due to failure is utilised as a significant parameter in design bench height and berm width.

Each attribute must be defined statistically in order to be able to complete a probabilistic analysis of these components. A Monte Carlo method is typically utilised due to the complexity of the variables when conducting this type of analysis. When assessing the stability for a particular slope orientation, the procedure is outlined as:

- Determine of the potential failure modes through a kinematic analysis.

- Determine the maximum break back for each defined cell. In turn, assess:

- The probability of occurrence for each structure set.

- Calculate the theoretical break back for each failure mode occurrence - ensure the statistical distribution of the dip, dip direction, length and spacing are included.

- Construct the geometry of the failure mode.

- Calculate the stability of the constructed geometry.

- Evaluate the break back for other failure modes.

- Calculate the maximum break back for all failure modes and add this to the theoretical break back model for the slope.

- Combine these results into a cumulative probability density function for the break back.

- Convert the break back distance distribution to an equivalent bench face angle distribution.

This process adequately covers the probability of break back occurrence, which can be completed per design sector. The break back distance can be converted to equivalent bench face angle and therefore an appropriate berm width based on the acceptance criteria. It is imperative, where possible, to correctly survey the bench face toe and crest and compare the achieved design with what was anticipated in the detailed assessment. An empirical correction factor of what can theoretically be achieved may then be applied per design sector.

\subsection{Rocscience RocPlane and SWedge}

The methodology of calculating spill radii for both conical- and pyramidal-shaped instabilities was presented by Gibson et al. (2006). These methodologies have been utilised by Rocscience in their RocPlane and sWedge software.

A review of the options available for the Rocscience RocPlane and SWedge software was compiled based on the tutorials published by Rocscience for bench design (Roscience n.d. a, b). Two principal approaches are described for the bench design analysis tool:

- The managed approach: The concept that it is acceptable to use steep bench face angles and allow some failures to occur as long as safety is not compromised. While there is a greater amount of spilled material on the bench, the economics behind a steeper slope and instituting bench cleaning procedures are far more favourable than a shallower slope with larger berm widths.

- The quantitative hazard assessment: This includes the estimation of a variety of instability sizes, the likelihood of forming that instability, the likelihood that the instability will slide and an estimation of the PoF. 
The minimum bench width is defined as the sum of the back-break distance and the spill width. If this value is greater than the actual berm width defined in the input parameters, material may spill over the bench and move down the slope into the operating levels below. As both the back-break distance and spill width will have a distribution of values, a minimum bench width is defined for each bench face angle according to the bench retention factor. The acceptance criteria for the minimum berm width is a catchment potential of between 70 and $85 \%$.

\subsection{Assessment of the minimum berm width required utilising published criteria}

Ritchie (1963) is the first publication that challenges the concept of the design of berm width to adequately contain rockfall for highway shoulders. A relationship between the width of the fall-out versus the height and angle of the slope is provided for selecting adequate berm width for design as is known as the Ritchie Criterion.

In 1977, Piteau \& Martin presented formula for designing the minimum berm width required for a bench design. This is the first instance whereby the cross-sectional and the dip or plunge of the failure were taken into consideration as well as the angle of repose, however, this formula does not take the true geometry or the wedge or the bulking/swell factor into consideration.

Martin \& Piteau (1977) later present two methods on which slope design can be based, these are a conservative or a managed approach. A process for calculating the cross-sectional area of a failure, the radius of the failed material taking the angle of repose into consideration, and the minimum berm width required to hold the failure size is presented based on the earlier work, case study and formula provided in Piteau \& Martin (1977).

Pierson et al. (1994) present the Oregon Ditch Standard, which is based on a number of tested rockfall scenarios for determining the required berm width for highway shoulder. Pierson et al. (1994) discuss that ditches true to the Ritchie Criterion are seldom constructed and therefore, that the criterion has been adjusted and is not actually applicable as the construction is not an accurate reflection of the design recommendations. The Oregon Ditch Standard is not typically applied to bench design analysis for open pit slopes.

Hustrulid et al. (2001) present the Modified Ritchie Criterion, which considers rockfall. However, the applicability of the criterion due to the fact that ditches are not constructed is not highlighted as in Pierson et al. (1994). The Modified Ritchie Criterion is considered to be conservative for containing rockfall. As the problem of rockfall and failure containment is complex, a risk-management perspective should be taken into consideration when compiling an open-pit design.

Gibson et al. (2006) present a methodology for calculating spill radii utilising a conical (does not take wedge geometry into account) and pyramidal (does take wedge geometry into account) distribution of failed material. Between the two formulae, it is recommended that the lesser of the two spill radii values is utilised for design purposes. The principal design considerations for berm width such as the angle of repose, swelling or bulk factor as well as the bench retention factor are included in the formula.

Haines et al. (2006) present formula for the derivation of spill berm width using a bulk or swell factor of 1.5. Martin \& Piteau (1977) also stated an adjustment factor of 1.5 for the swelling or bulk factor should it not be taken into consideration. It would appear that the formula presented does not take the angle of repose, bench retention factor nor the failure geometry into account. Although not published, there is no reason why the bench retention factor should not be applied to the volume utilised in the formula.

Jermy et al. (2011) conduct a comparison of the Modified Ritchie Criterion (Ritchie 1963) which provided a static berm width, whilst the Haines Criterion (Haines et al. 2006) and the conical distribution formula from Gibson et al. (2006) tended to overestimate the berm widths required as the wedge geometry and failed material distribution were not taken into consideration. The pyramidal Gibson formula (Gibson et al. 2006) did, however, provide a more realistic estimate of the design berm width.

Gibson \& Paul (2016) present a comparison of the Gibson formula (Gibson et al. 2006) and the results obtained by Frac_Rock, which demonstrates that the Gibson formula overestimates the berm width required by approximately 10 to $20 \%$. 
The Appendix provides a comparison of the published criteria, noting if they are empirical or formula-based, and if factors such as the bench height, bench face angle, plunge of intersection, angle of repose, volume of material and the bulk/swell factor were taken into consideration.

\section{$4 \quad$ Bench design: an example of an advanced dataset assessment technique}

The assessment of the minimum required berm width using advanced analysis techniques, database assessment methods and published criteria are discussed in the proceeding sections.

\subsection{Bench design methodology using advanced analysis techniques}

A flow chart detailing the bench design methodology based on the published literature, available software and advanced dataset analysis techniques is presented in Figure 1. The flow chart describes the processes for defining the outcome of the analysis, the data collection stage, the empirical slope design, the kinematic analysis, model compilation, acceptance criteria, input parameters, practical considerations, managed and quantitative design approaches, advanced dataset assessment methods, advanced assessment of the minimum berm width required utilising published criteria and the outcome of the analysis.

\subsection{Dataset assessment methods}

The published dataset assessment methods may be summarised as:

- FoS cutoff of $>1$, Piteau \& Martin (1977).

- FoS cutoff of $>1.1$, Holley et al. (2006) and Grenon \& Laflamme (2011) (iterations with a FoS > 1.1 were discounted).

- Jermy et al. (2011) focussed specifically on generated wedge iterations that had FoS values between 1.2 and 1.8 for larger spill volumes. The sensitivity of the FoS for larger failures $<1.2$ was defined.

- Hafid et al. (1992) focus on the largest wedges by volume.

- Remove the largest $20 \%$ and smallest $40 \%$ of wedge iterations based on volume (Holley et al. 2006).

- Utilise the whole dataset, regardless of FoS or volume (Coetsee 2014).

- Do not apply the berm retention factor criteria to this data, so that a full assessment of the spill radii can be made (apply design criteria at the end of the analysis).

\subsection{Assessment of the minimum berm width required utilising advanced dataset analysis techniques}

In order to conduct a detailed assessment of the planar and wedge sliding implications for berm width, two plots may be compiled for each section line. The first plot can illustrate the percentage of instabilities per spill radius bin (metre increments) and the second plot can illustrate the break back distance range per spill radius (same metre increments) required utilising the same database. The database must be a combined dataset for planar and wedge sliding iterations for each model, per section line. Figure 2 illustrates an example of spill radii and percentage of instabilities and the crest break back range per spill radii distance.

By applying a population cutoff (case study specific) of the percentage of instabilities per metre increment (spill radius), the maximum berm width required and the maximum break back distance (for the berm above) can be delineated. In the case of Figure 2, the percentage population under $5 \%$ for spill radii greater than $6 \mathrm{~m}$ is very low. By assessing each the plots compiled for each section line, for both planar and wedge sliding, the percentage population cutoff can be decided. 
The population cutoff, whilst case study-specific, should capture a point in the data presented whereby the majority of the population of instabilities has been taken into consideration. By not applying the berm retention factor to this data, the true spread of spill widths can be assessed as well as the likely break back range per spill radii distance. By applying the berm retention factor, this data comparison would not be accurate.

In order to compile the percentage of instabilities per spill radius increment and the associated break back distance range, the following process is required:

- Assigning a nominal cohesion value in order to allow SWedge to calculate the spill radius per valid iteration (a nominal cohesion value of $0.05 \mathrm{Mpa}$ is required in order to allow SWedge to calculate the spill radius per valid iteration).

- The FoS should not be taken into consideration but rather the spill radius and therefore, the minimum berm width required per valid iteration or potential failure.

- The berm retention capacity of the failure volume should not be applied to the data.

- The combined total number of valid planes or wedges per section line*.

- The spill radius calculated per valid wedge*.

*These outputs are provided in Microsoft Excel, for each SWedge model compiled. 


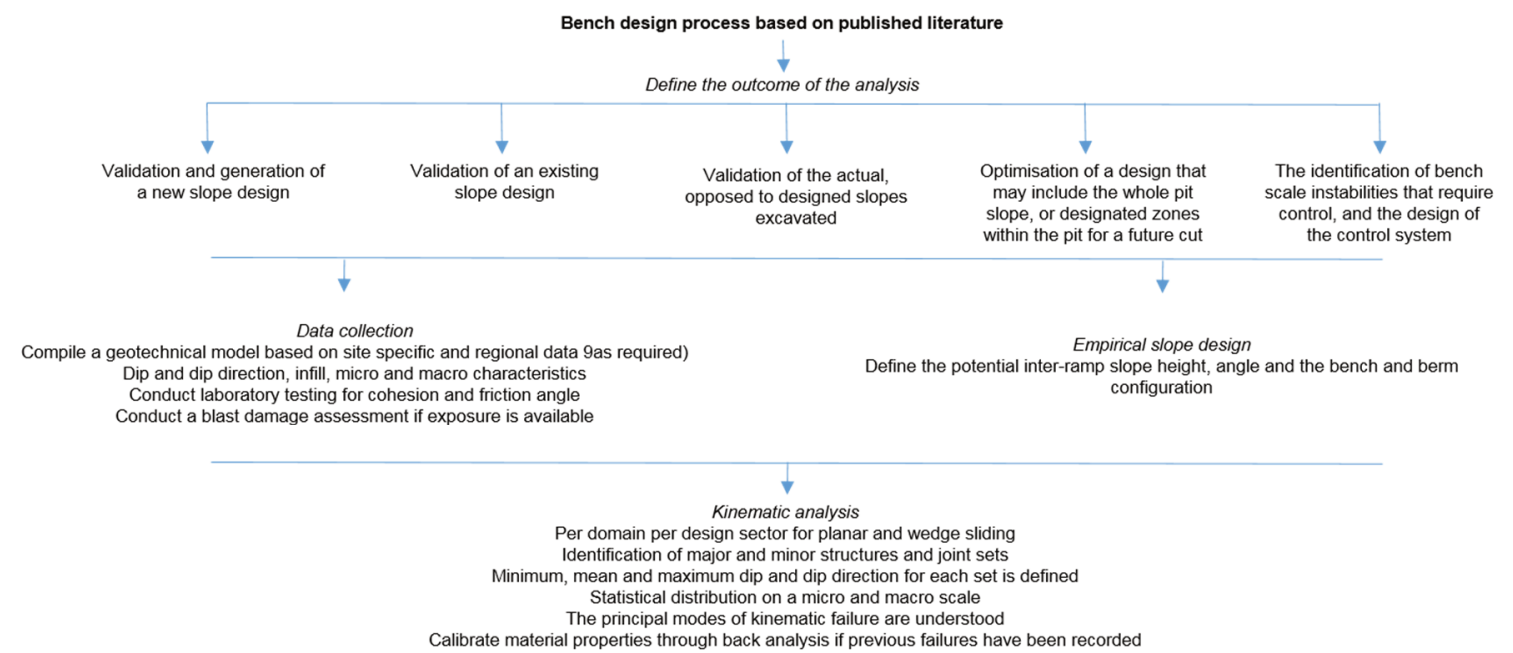

Calibrate material properties through back analysis if previous failures have been recorded calibrated if possible)

Input parameters

Reduction of the cohesion and friction angle values to represent in-pit opposed to in-situ conditions and compare Removal of the macro condition to planar

Practical considerations
Multi bench failure, ravelling, blast spill from higher cuts, time period of exposure, climate, weathering, blasting practices, operator experience

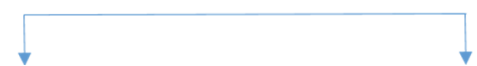

Managed approach to design

Total probability of failure plot

Normalised frequency of failed wedges

Minimum berm width plot Miller (1983), Miller, Girard \& McHugh (2000) and Whyatt, Miller \&
Dwyer (2004)

Cell probability of occurrence plot Cell cumulative probability of occurrence plot Cell probability of sliding plot Cell probability of failure plot

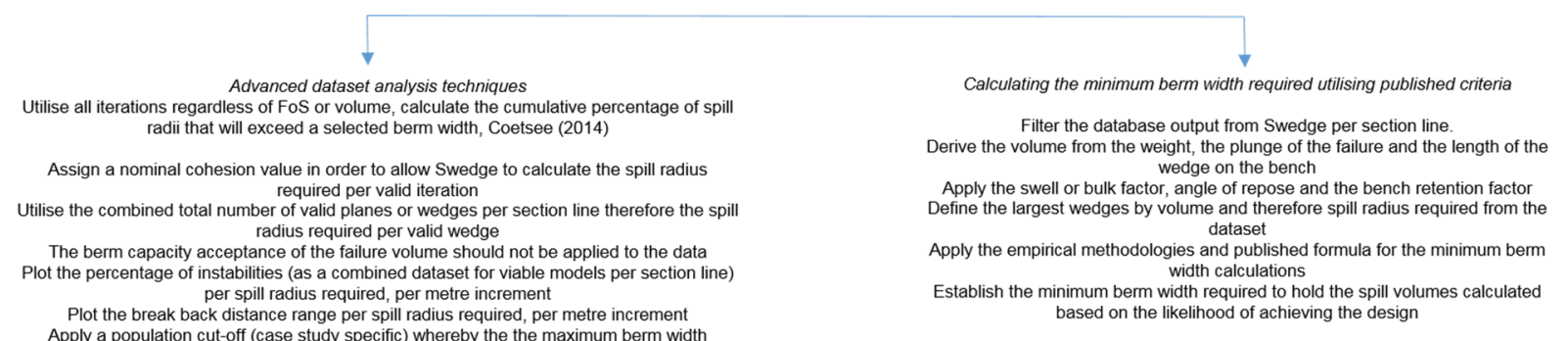

the

Apply a population cut-off (case study spectic) whereby the the maximum berm width

required and the maximum break back distance (for the berm above) can be delineated design

Outcome of the analysis

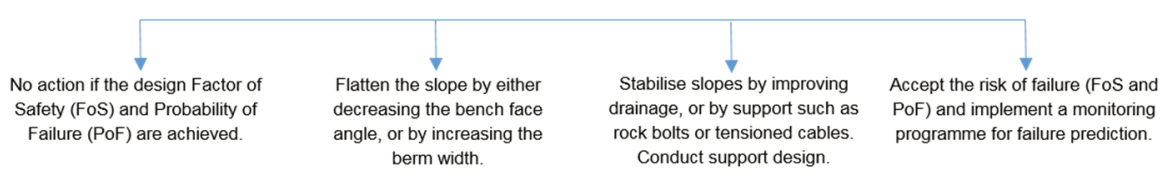

Figure 1 Bench design methodology based on published literature, available software and advanced dataset analysis techniques 

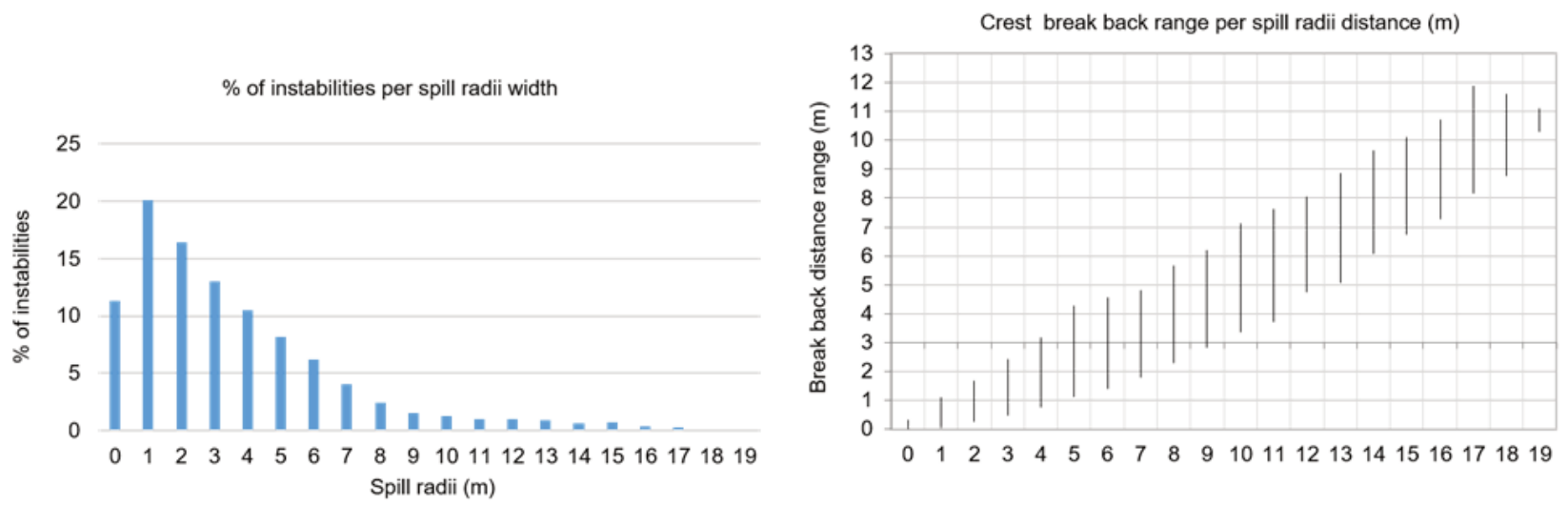

Figure 2 Example of spill radii and percentage of instabilities and the crest break back range per spill radii distance

The FoS per iteration should not be taken into consideration, as it is not an absolute value. The FoS will change dependent on the joint conditions over time. Therefore, what may be considered an acceptable FoS for a plane or wedge shape geometry may not be acceptable at a later date due to weathering, blasting, etc.

The information that the plots provide includes:

- The likelihood in the form of the percentage of the population of valid planes and wedges that will require a certain spill width radius and therefore a minimum berm width.

- The break back distance range behind the crest that is likely to occur per spill width radius bin. This provides an indication of how much berm loss is likely to occur on the berm above, and what berm width is required to contain the instability, should it occur.

Once the plots have been compiled for each section line and the percentage cutoff has been applied, a table can be populated with the section line and failure type, percentage cutoff of spill radius, therefore maximum berm width required and the maximum break back distance, which is illustrated in Table 1.

Table 1 Maximum berm width required and maximum break back distance per section line (example)

\begin{tabular}{lll}
\hline Section and failure type & $\begin{array}{l}\text { \% cutoff of spill radius, therefore } \\
\text { maximum berm width required }(\mathbf{m})\end{array}$ & $\begin{array}{l}\text { Maximum break back } \\
\text { distance }(\mathrm{m})\end{array}$ \\
\hline $\begin{array}{l}\text { Section 1, planar } \\
\text { (fictitious example) }\end{array}$ & $5 \%$ and $10 \mathrm{~m}$ & $1.5 \mathrm{~m}$ \\
\hline
\end{tabular}

\subsection{Advanced method for calculating and comparing the minimum berm width utilising the published criteria}

In order to calculate the minimum berm width utilising the criteria discussed, the database per section line for both the planar and the wedge sliding analysis can be filtered for the input parameters required for the various formulae. The database is a combined dataset for planar and wedge sliding iterations for each model, per section line.

The following information should be derived per section line per valid iteration:

- Volume, calculated from the SWedge weight output as SWedge does not provide direct volume values.

- Plunge of the failure.

- Length of the plane or wedge on the berm. 
The swelling or bulk factor and the angle of repose should be assigned based on the acceptance criteria.

By applying a case specific percentage cutoff to the database, the maximum berm width required and the maximum break back distance per failure mode and section line can be derived for this approach too. The largest weight and therefore failure volume for the maximum berm width bin in the database (per failure mode, per section line) can be filtered and then utilised to compare the minimum berm width calculated using the published criteria.

The criteria to be compared include:

- Piteau minimum berm width (Piteau \& Martin 1977).

- Modified Ritchie Criterion (Hustrulid et al. 2001).

- Haines minimum berm width (Haines et al. 2006), with and without the bench retention factor applied.

- Gibson Pyramidal and Conical minimum berm width (Gibson et al. 2006), with and without the bench retention factor applied.

This method provides a departure from published information in that it includes the advanced dataset analysis technique.

Table 2 details the results of the minimum berm width required utilising the published methods and applying the various acceptance criteria.

Table 2 Results of the comparison (example)

\begin{tabular}{|c|c|c|c|c|c|c|}
\hline \multirow[b]{2}{*}{$\begin{array}{l}\text { Section - Planar } \\
\text { Analysis }\end{array}$} & \multicolumn{6}{|c|}{ Criteria } \\
\hline & 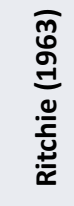 & 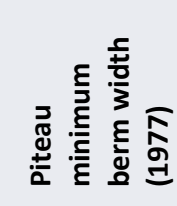 & 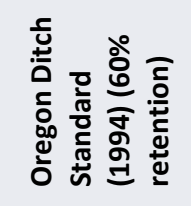 & 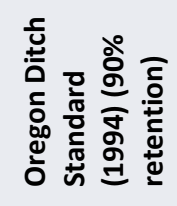 & 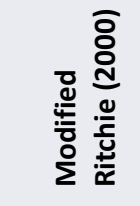 & 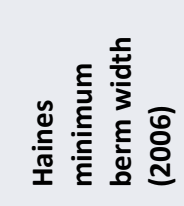 \\
\hline $\begin{array}{l}\text { Section 1, option } 1 \\
\text { (fictitious example) }\end{array}$ & 6 & 10.22 & 4.40 & 14.00 & 9.3 & 5.37 \\
\hline
\end{tabular}

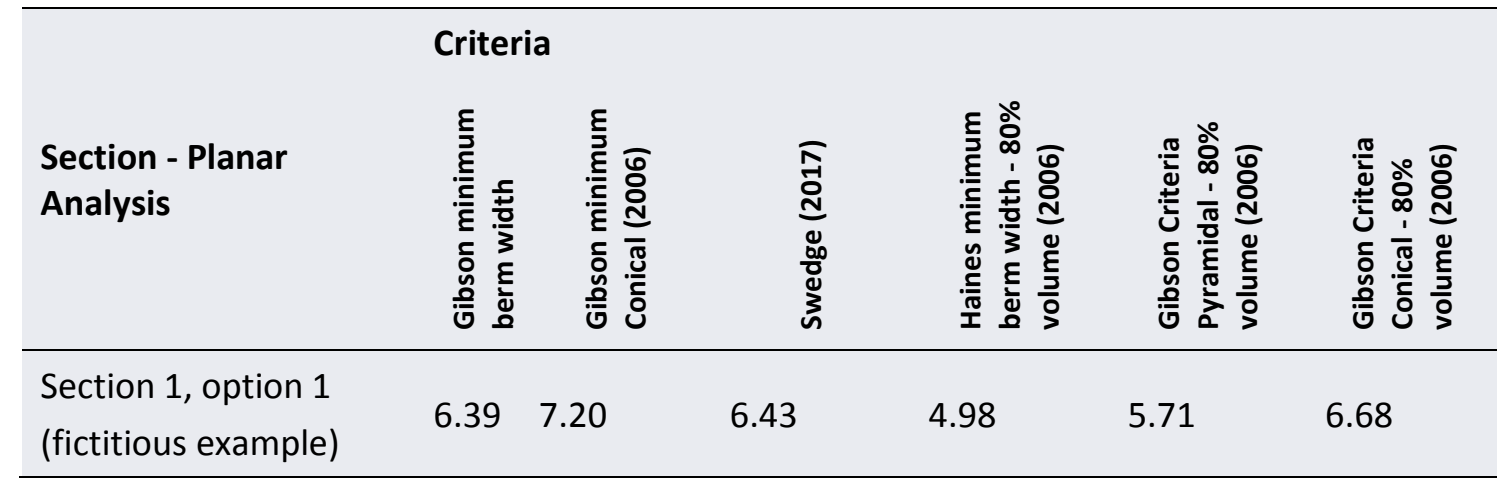

\section{Conclusion}

Having completed the bench design analysis, an assessment of the results can be conducted.

Dependent on the desired outcome of the analysis (refer to Section 2.2), the results can be assessed with the design criteria in mind. 


\subsection{Published criteria}

The advanced method for calculating and comparing the minimum berm width utilising the published criteria provides useful information on the spread of minimum berm widths calculated based on empirical formulae as well as formulae developed to capture site-specific conditions.

The comparison of the various berm design criteria illustrated that the Ritchie Criterion (Ritchie 1963), Oregon Ditch Standard (Pierson et al. 1994) and Modified Ritchie Criterion (Hustrulid et al. 2001) give a constant berm width as they are empirically based.

The Ritchie Criterion (Ritchie 1963) and the Oregon Ditch Standard (Pierson et al. 1994) for a 60\% retention factor provide minimum berm widths of $6.25 \mathrm{~m}$ and $6.20 \mathrm{~m}$, respectively. A minimum berm width of $14 \mathrm{~m}$ is prescribed by the Oregon Ditch Standard (Pierson et al. 1994) for a $90 \%$ retention factor. This information is the same for both the planar and wedge sliding assessment as the bench height and bench face angle dictate the empirical recommendation for these criteria.

The Piteau minimum berm width values (Piteau \& Martin 1977) are typically higher than those calculated for the Haines minimum berm width (Haines et al. 2006) and Gibson pyramidal and conical berm widths (Gibson et al. 2006).

The Piteau formulae provide a conservative estimation of the minimum berm width required. Interestingly, a bulk factor has not been applied to these values, as it is not considered in the original formulae. Should a bulk factor of 1.3 been applied (by multiplying the berm width by 1.3 for shallow failures or applying the square root for steeply dipping failures), the minimum berm widths calculated would be conservative.

The Haines minimum berm width (Haines et al. 2006) values are typically lower than that of the Gibson pyramidal and conical berm widths (Gibson et al. 2006). The formula does not take the angle of repose, bench retention factor nor the failure geometry into account and therefore may be considered as underestimating the minimum berm widths required as the formula is not specific to the conditions that may be encountered.

The Gibson pyramidal minimum berm widths are typically higher than those calculated using the conical minimum berm widths formula. The conical minimum berm width formula does not take the wedge geometry into consideration and it is stated that it may tend to overestimate the minimum berm width (Gibson et al. 2006). Should this be the case, it is expected that the conical minimum berm widths would all be greater than those calculated using the pyramidal formula. This does not hold true with the Kao dataset, and a more detailed assessment utilising project datasets opposed to test datasets as per the publication should be explored.

Gibson pyramidal and conical berm widths (Gibson et al. 2006) are utilised by SWedge to calculate the minimum berm width. It is observed that SWedge selects the lesser of the two calculated values based on the Gibson conical and pyramidal formula, as recommended by Gibson et al. (2006) at the time of the compilation of this work. Whilst this recommendation is published, it is pertinent to confirm local site conditions and make a decision based on the geotechnical model and the data available. Jermy et al. (2011) state that the pyramidal formula was the most relevant to their study.

By applying the $80 \%$ berm retention factor to the potential failure volume, the minimum berm widths were recalculated for Haines minimum berm width (Haines et al. 2006) and Gibson pyramidal and conical berm widths (Gibson et al. 2006) in order to finalise the bench design.

\subsection{Advanced dataset techniques}

By assessing the plot data compiled (refer to Section 4.3 and Figure 2), the maximum berm width calculated (having applied the spill radii cutoff) and the maximum break back distance can be added and compared to the actual design, planned design or calibration assessments. This completes the assessment of the minimum berm width required utilising advanced dataset techniques. 


\section{Appendix Comparison of the published criteria}

\begin{tabular}{|c|c|c|c|c|c|c|c|c|}
\hline Criteria & Reference & Empirical & $\begin{array}{l}\text { Bench height } \\
\text { (m) }\end{array}$ & $\begin{array}{l}\text { Bench face } \\
\text { angle }\left({ }^{\circ}\right)\end{array}$ & $\begin{array}{l}\text { Plunge of } \\
\text { intersection }\left({ }^{\circ}\right)\end{array}$ & $\begin{array}{l}\text { Angle of } \\
\text { repose }\left({ }^{\circ}\right)\end{array}$ & $\begin{array}{l}\text { Volume of } \\
\text { material }\left(\mathrm{m}^{3}\right)\end{array}$ & $\begin{array}{l}\text { Bulk or swell } \\
\text { factor }\end{array}$ \\
\hline Ritchie Criterion & Ritchie (1963) & Yes & Yes & Yes & - & - & - & - \\
\hline $\begin{array}{l}\text { Modified Ritchie } \\
\text { Criterion }\end{array}$ & $\begin{array}{l}\text { Hustrulid et al. } \\
\text { (2001) }\end{array}$ & Yes & Yes & Yes & - & - & - & - \\
\hline $\begin{array}{l}\text { Minimum } \\
\text { required berm } \\
\text { width }\end{array}$ & $\begin{array}{l}\text { Piteau \& Martin } \\
\text { (1977) and Martin \& } \\
\text { Piteau (1977) }\end{array}$ & - & Yes & Yes & Yes & Yes & - & Yes \\
\hline $\begin{array}{l}\text { Oregon Ditch } \\
\text { Standard }\end{array}$ & Pierson et al. (1994) & Yes & Yes & - & - & - & - & - \\
\hline $\begin{array}{l}\text { Haines minimum } \\
\text { berm width }\end{array}$ & Haines et al. (2006) & - & - & - & - & - & Yes & Yes \\
\hline $\begin{array}{l}\text { Gibson minimum } \\
\text { berm width } \\
\text { conical }\end{array}$ & Gibson et a. (2006) & - & Yes & Yes & - & Yes & Yes & Yes \\
\hline $\begin{array}{l}\text { Gibson minimum } \\
\text { berm width } \\
\text { pyramidal }\end{array}$ & Gibson et al. (2006) & - & Yes & Yes & Yes & Yes & Yes & Yes \\
\hline $\begin{array}{l}\text { Modified Gibson } \\
\text { minimum berm } \\
\text { width }\end{array}$ & Gibson \& Paul 2016 & Yes & \multicolumn{6}{|c|}{ Apply a reduction of between $10 \%$ and $20 \%$ to either formula } \\
\hline
\end{tabular}




\section{References}

Abrahams, G 2015, Bench-berm design: who really cares?, SRK Consulting (South Africa) (Pty) Ltd, Cape Town.

Carvalho, J ca. 2012, Slope stability analysis for open pits, Golder Associates Ltd, Mississauga.

Coetsee, S 2014, 'An overview of bench design for cut slopes', Proceedings of the 8th South African Young Geotechnical Engineers Conference, The South African Institution of Civil Engineers, Stellenbosch, pp. 561-571.

Gibson, WH, de Bruyn, IA \& Walker, DJ 2006, 'Considerations in the optimisation of bench face angle and berm width geometries for open pit mines', Proceedings of the International Symposium on Stability of Rock Slopes in Open Pit Mining and Civil Engineering, The Southern African Institute of Mining and Metallurgy, Johannesburg, pp. 557-578.

Gibson, W \& Paul, J 2016, Comparison for estimating volume of failed wedges, SRK Consulting (Australasia) Pty Ltd, Perth.

Grenon, M \& Hadjigeorgiou, J 2010, 'Integrated structural stability analysis for preliminary open pit design', International Journal of Rock Mechanics and Mining Sciences, pp. 450-460.

Grenon, M \& Laflamme, AJ 2011, 'Inter-ramp and bench design of open pit mines: the Portage pit case study', Canadian Geotechnical Journal, pp. 1601-1615.

Haines, A, Voulgaris, P, Walker, D \& de Bruyn, I 2006, 'Geotechnical design considerations for the proposed Oyu Tolgoi open pits, Southern Mongolia', Proceedings of the International Symposium on Stability of Rock Slopes in Open Pit Mining and Civil Engineering, The Southern African Institute of Mining and Metallurgy, Johannesburg, pp. 133-154.

Hafid Baroudi, D, Hantz, PD \& Piguet, JP 1992, 'Bench stability in open pit mines: A methodology for jointed rock masses', Regional Conference on Fractured and Jointed Rock Masses, International Society for Rock Mechanics, Lisbon, pp. 67-72.

Hoek, E \& Bray, JW 1981, Rock slope engineering, The Institute of Mining and Metallurgy, London.

Holley, K, Skayman, P \& Zhiwei, H 2006, 'Geotechnical design for the open pits at Tanjianshan, China', Proceedings of the International Symposium on Stability of Rock Slopes in Open Pit Mining and Civil Engineering, The Southern African Institute of Mining and Metallurgy, Johannesburg, pp. 483-508.

Hustrulid, WA, McCarter, MK \& Van Zyl, DJA 2001, Slope Stability in Surface Mining, Society for Mining, Metallurgy, and Exploration, Englewood.

Jermy, C, Kuppusamy, V, Fietze, CP \& Hornsby, PK 2011, 'Open pit bench failure volume analysis and berm design - is it realistic?', Proceedings of the International Symposium on Rock Slope Stability in Open Pit Mining and Civil Engineering, Canadian Rock Mechanics Association, Vancouver.

Martin, D \& Piteau, DR 1977, 'Select berm width to contain local failures', Engineering and Mining Journal, vol. 178, no. 6, pp. 161-164.

Miller, S 1983, 'Probabilistic analysis of bench stability for the use in designing open pit mines', Proceedings of the 24th US Symposium on Rock Mechanics, American Rock Mechanics Association, Alexandria, pp. 621-629.

Miller, S, Girard, JM \& McHugh, EL 2000, 'Computer modelling of catch benches to mitigate rockfall hazards in open pit mines', in J Girard, M Liebman, T Doe \& C Breeds (eds), Proceedings of the 4th North American Rock Mechanics Symposium, AA Balkema, Boca Raton, pp. 539-535.

Pierson, L, Davis, SA \& Pfeiffer, TJ 1994, The nature of rockfall as the basis for a new fallout area design criteria for 0.25: 1 slopes, Oregon Department of Transportation, Salem.

Piteau, D \& Martin, DC 1977, 'Slope stability analysis and design based on probability techniques at Cassiar Mine', CIM Bulletin, vol. 70, no. 779, pp. 139-150.

Read, J \& Stacey, P 2009, Guidelines for Open Pit Slope Design, CSIRO Publishing, Collingwood.

Ritchie, A 1963, Evaluation of rockfall and its control, Washington State Highway Commission, Washington.

Rocscience n.d .a, Bench Design in Rocplane Tutorial, Rocsience, Toronto.

Rocscience n.d. b, Bench Design in SWedge Tutorial, Rocscience, Toronto.

Whyatt, J, McLaughlin, M \& Miller, S 2004, 'Analysis of bench crest performance at the Yellowstone Mine', in M McLaughlin \& R McNearny (eds), Proceedings of the 39th Symposium on Engineering Geology and Geotechnical Engineering: Research to Practice, Montana Tech, Butte, pp. 149-163.

Whyatt, J, Miller, S \& Dwyer, JG 2004, NIOSH computer programs for bench crest failure analysis in fractured rock, The National Institute for Occupational Health and Safety, Cincinnati, https://www.cdc.gov/niosh/mining/UserFiles/works/pdfs/ncpfb.pdf 